\title{
ARTICLE \\ Voluntary wheel running promotes resilience to chronic social defeat stress in mice: a role for nucleus accumbens $\Delta$ FosB
}

Joram D. Mul $\mathbb{D}^{1,2,7}$, Marion Soto ${ }^{1}$, Michael E. Cahill ${ }^{3}$, Rebecca E. Ryan ${ }^{1}$, Hirokazu Takahashi ${ }^{1}$, Kawai So ${ }^{1}$, Jia Zheng ${ }^{1}$, Denise E. Croote ${ }^{1}$, Michael F. Hirshman ${ }^{1}$, Susanne E. la Fleur ${ }^{4,5}$, Eric J. Nestler ${ }^{3}$ and Laurie J. Goodyear ${ }^{1,6}$

Elucidating mechanisms by which physical exercise promotes resilience, the brain's ability to cope with prolonged stress exposure while maintaining normal psychological functioning, is a major research challenge given the high prevalence of stress-related mental disorders, including major depressive disorder. Chronic voluntary wheel running (VWR), a rodent model that mimics aspects of human physical exercise, induces the transcription factor $\triangle F o s B$ in the nucleus accumbens (NAc), a key reward-related brain area. $\triangle F o s B$ expression in NAc modulates stress susceptibility. Here, we explored whether VWR induction of NAc $\triangle$ FosB promotes resilience to chronic social defeat stress (CSDS). Male young-adult C57BL/6J mice were single housed for up to $21 \mathrm{~d}$ with or without running wheels and then subjected to $10 \mathrm{~d}$ of CSDS. Stress-exposed sedentary mice developed a depressive-like state, characterized by anhedonia and social avoidance, whereas stress-exposed mice that had been wheel running showed resilience. Functional inhibition of NAc $\triangle$ FosB during VWR, by viral-mediated overexpression of a transcriptionally inactive JunD mutant, reinstated susceptibility to CSDS. Within the NAC, VWR induction of $\triangle$ FosB was CREB-dependent, associated with altered dendritic morphology, and medium spiny neuron (MSN) subtype specific in the NAc core and shell subregions. Finally, when mice performed VWR following the onset of CSDS-induced social avoidance, VWR normalized such behavior. These data indicate that VWR promoted resilience to CSDS, and suggest that sustained induction of $\triangle$ FosB in the NAc underlies, at least in part, the stress resilience mediated by VWR. These findings provide a potential framework for the development of treatments for stress-associated mental illnesses based on physical exercise.

Neuropsychopharmacology (2018) 43:1934-1942; https://doi.org/10.1038/s41386-018-0103-z

\section{INTRODUCTION}

Major depressive disorder is a common psychiatric condition that results in an enormous social and financial burden on modern society [1, 2]. Although some people develop depressive episodes following acute or chronic episodes of stress, others successfully cope with adversity. Such resilience is associated with the development of behavioral, molecular, and psychological adaptations to stress $[3,4]$. Despite recent advances, the neurophysiological processes underlying resilience are still incompletely understood. Full understanding of these processes could offer a crucial dimension for the development of novel therapeutic treatments that prevent stress-related disorders.

$\Delta$ FosB, a Fos family member with unique protein stability, heterodimerizes with Jun family proteins to form activator protein1 transcription factor complexes that regulate the transcription of hundreds of genes $[5,6]$. A large literature has demonstrated that $\triangle \mathrm{FosB}$ in the nucleus accumbens (NAc), a key reward-related brain area, is strongly implicated in neuronal adaptations to drugs of abuse and stress [7-9]. Within the NAc, $90-95 \%$ of all neurons are projecting medium spiny neurons (MSNs), which are present in approximately equal populations based on their selective expression of dopamine receptor D1 or D2, as well as other genes [10, 11]. These two MSN subtypes, hereafter called D1-MSNs or D2MSNs, play distinct and often opposing roles in depressive- and addictive-like behavior [12-14].

Chronic social defeat stress (CSDS) is an ethologically valid rodent model that induces long-term physiological and behavioral depressive-like phenotypes [15]. Overexpression of $\Delta$ FosB specifically in the NAc promoted resilience to CSDS, whereas NAcspecific overexpression of $\Delta$ cJun, a transcriptionally inactive truncated cJun mutant that antagonizes $\Delta$ FosB activity, promoted susceptibility to CSDS [16]. Intriguingly, although mice exposed to CSDS develop behavioral and metabolic disturbances, a substantial part does not and are therefore termed 'resilient' [17]. Molecular follow-up of these cohorts revealed that high levels of $\triangle$ FosB in NAc D1-MSNs are associated with stress resilience, whereas high levels of $\triangle$ FosB in NAc D2-MSNs are associated with stress susceptibility [18].

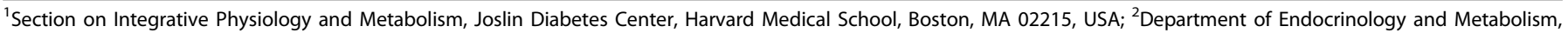

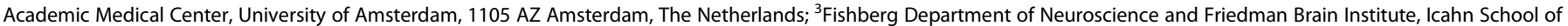

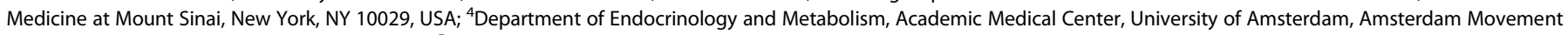

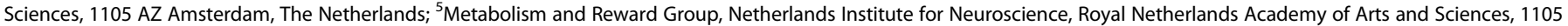
BA Amsterdam, The Netherlands and ' ${ }^{6}$ Department of Medicine, Brigham, and Women's Hospital, Harvard Medical School, Boston, MA 02115, USA Correspondence: Joram D. Mul (j.d.mul@amc.uva.nl)

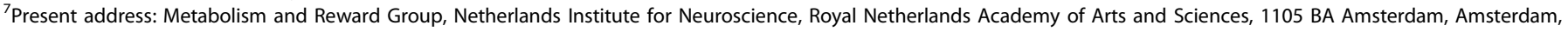
The Netherlands
} 
Physical exercise has beneficial effects on stress-related mental disorders [19-26], indicating tremendous and low-cost clinical potential. Despite these profound beneficial effects, the underlying neurobiology remains unclear [22]. Voluntary wheel running (VWR), a rodent model that mimics aspects of human physical exercise training, can be used for the preclinical etiological and mechanistic examination of resilience conferred by this behavioral intervention [22]. In rats and mice, 4-6 weeks of VWR increase $\triangle$ FosB expression in the NAc [27-30]. Prior indirect analysis in rats using dynorphin and enkephalin expression (markers of D1- and D2-MSNs, respectively) suggested that VWR induced $\triangle \mathrm{FosB}$ preferentially in NAC D1-MSNs [30], yet the functional consequences of this accumulation has not been directly investigated to date.

Here, we aimed to examine whether VWR promotes resilience to CSDS, and if NAc $\triangle$ FosB is involved. Presence of a depressivelike state was determined based on social avoidance and anhedonia, behavioral reward-related deficits that are controlled by the NAc, associated with depression and which can be objectively measured in rodents [31, 15]. Young-adult male C57BL/6J mice were housed for up to $21 \mathrm{~d}$ with or without running wheels and then subjected to $10 \mathrm{~d}$ of CSDS. NAc-specific viral-mediated overexpression of $\triangle \mathrm{JunD}$, a transcriptionally inactive truncated JunD mutant that antagonizes $\Delta$ FosB activity [16], was then utilized to directly test the functional consequences of VWR induction of NAC $\triangle F$ FosB on stress-related behaviors. We also investigated if VWR after the onset of CSDSinduced social avoidance was able to reverse such aberrant behavior. Finally, several aspects of VWR-induced adaptations in the NAc, including MSN subtype-specific $\triangle \mathrm{FosB}$ induction, upstream signaling cascades, and dendritic spine morphology, were investigated.

\section{MATERIALS AND METHODS}

Animals

All experiments were done in accordance with the policies set out by the institutional animal care and use committee (IACUC) at the Joslin Diabetes Center. C57BL/6J mice (http://jaxmice.jax.org/ strain/000664.html) were group housed and acclimated to the Joslin Diabetes Center animal facility for $7 \mathrm{~d}$ and housed individually at the start of experiments. Drd1a-TdTomato mice (http://jaxmice.jax.org/strain/016204.html) were bred in-house to wild-type C57BL/6J mice (http://jaxmice.jax.org/strain/000664. html) to generate Drd1a-TdTomato ${ }^{+/}$mice. Experimental groups were body weight matched at the start of the experiments. Animals were maintained at $23-25^{\circ} \mathrm{C}$ on an artificial 12 -h light/ dark cycle (lights on from 06:30) with ad libitum access to water and pelleted low-fat chow diet (9F 5020 Lab Diet, 23\% protein, $55 \%$ carbohydrate, and $22 \%$ fat, $3.56 \mathrm{kcal} / \mathrm{g}$, PharmaServ Inc.). Male mice were used for all studies.

\section{Voluntary wheel running}

VWR was performed as previously described [32]. In short, after acclimatization, 10-week old mice were housed without (sedentary) or with free (VWR) access to a running wheel $(24 \mathrm{~cm}$ diameter, $8 \mathrm{~cm}$ wide; Nalgene, Rochester, NY) for the indicated experimental time. Wheel revolutions were measured daily or at indicated times using odometers. Because cage enrichment can modulate $\triangle$ FosB in the NAc [33], mice housed with a blocked running wheel served as an additional control group, where indicated.

\section{Metabolic measurements}

Body weight and available food were measured at the start and end of indicated VWR durations. Water intake was measured during the indicated time using two custom-made non-leaking drinking pipettes, both containing water.
Immunoblotting

For all immunoblotting studies, running wheels remained active for the indicated time and food was removed at the onset of the dark phase. Mice were sacrificed 3-4 h into the dark phase by cervical dislocation, and brains were immediately isolated and snap-frozen in isopentane on dry ice. A separate cohort of mice was sacrificed during the light phase after $14 \mathrm{~d}$ of VWR. Isolated brains were subsequently emerged in Optimal Cutting Compound (Tissue-Tek) and cooled before being cut on a freezing microtome (Leica Microsystems, model VT1000S) until onset of the NAc (AP + 1.98 relative to bregma) [34]. NAc samples were bilaterally dissected using a dissection needle $(\varnothing 1 \mathrm{~mm})$ and sonicated on ice in $80 \mu \mathrm{l}$ protein extraction buffer containing phosphatase inhibitor mix 1 (Roche). Samples were centrifuged at $15,000 \times g$ for 25 min following sonication, and supernatant containing wholecell fractions was collected and processed for protein concentration determination using Bradford protein assays. For western blotting, $30 \mu \mathrm{g}$ of protein/sample were run on a $10 \%$ Criterion acrylamide gel from Bio-Rad, transferred to a nitrocellulose membrane, blocked with $5 \%$ bovine serum albumin (BSA), and incubated overnight using primary antibodies against FosB (\#2251; 1:1000; Cell Signaling Technology), CREB (\#9197; 1:1000; Cell Signaling Technology), pCREB (Ser ${ }^{133}$ ) (\#9198; 1:1000; Cell Signaling Technology), SRF (1:1000; Santa Cruz Biotechnology), pSRF (Ser ${ }^{103}$ ) (\#4261; 1:1000; Cell Signaling Technology), and GAPDH (\#2118; 1:1000; Cell Signaling Technology). Antibodybound proteins were visualized on film using chemiluminescence detection reagents (Perkin-Elmer Life Sciences). Protein bands were scanned and quantitated by densitometry using ImageJ software (National Institutes of Health).

Brain perfusion and single label indirect immunofluorescence After $14 \mathrm{~d}$ of VWR, running wheels were blocked for $24 \mathrm{~h}$, resulting in the degradation of any residual full-length FosB protein such that all remaining immunoreactivity reflects $\Delta$ FosB [35]. Mice were anesthetized with an overdose of pentobarbital $(5 \mathrm{mg} / \mathrm{ml}$ saline; $90 \mathrm{mg} / \mathrm{kg}$ i.p.) and perfused transcardially with $10 \mathrm{ml} 1 \times$ phosphate-buffered saline (PBS) for $2 \mathrm{~min}$, followed by $20 \mathrm{ml}$ Histochoice fixative (Amresco) for $4 \mathrm{~min}$. Perfused brains were post-fixed in Histochoice for $48 \mathrm{~h}$ at $4{ }^{\circ} \mathrm{C}$, daily transferred to $5 \%$, $15 \%$, and $30 \%$ sucrose in PBS at $4{ }^{\circ} \mathrm{C}$, cryopreserved on dry ice in Optimal Cutting Compound (Tissue-Tek), and sliced into 10- $\mu \mathrm{m}$ coronal sections using a freezing microtome (Leica Microsystems, model VT1000S) and mounted. Slides were washed with $1 \times$ PBS before being blocked by incubation in $1 \times$ PBS with $5 \%$ normal goat serum and $0.3 \%$ Triton X-100. Rabbit anti-FosB antibody (1:200; \#2251, Cell Signaling Technology), diluted in $1 \times$ PBS with $0.3 \%$ Triton X-100 and $0.1 \%$ BSA, was applied to the sections for overnight incubation at $4{ }^{\circ} \mathrm{C}$. Sections were then incubated in Alexa Fluor 488 goat anti-rabbit lgG (1:1000; Life Technologies) at room temperature for $30 \mathrm{~min}$. Slides were cover-slipped with Prolong Gold Antifade reagent containing 4,6-diamidino-2-phenylindole (DAPI; Cell Signaling Technology).

\section{Imaging and cell counting}

Immunofluorescence was imaged on a Leica DM 4000B confocal microscope. Cell counting was performed using ImageJ software (National Institutes of Health). Images sampling bregma + 1.4 till +1.0 of the NAc core and shell subregions and the dorsal striatum were taken from two or three brain sections/animal. The NAc core and shell subregions were differentiated using corresponding diagrams from the Paxinos mouse brain atlas [34]. For the $\Delta \mathrm{FosB}$ and TdTomato co-staining experiment, approximately 150-300 total DAPI cells were counted per region of interest (ROI) per mouse, and then the number of TdTomato $^{+}$, TdTomato $^{+}: \Delta$ Fos $^{+}$, TdTomato $^{-}$, and TdTomato ${ }^{-}: \Delta$ FosB $^{+}$cells were counted in each ROI. If necessary, $\Delta$ FosB $^{+}$cell numbers were manually corrected for background staining of white fiber tissue. The total number of 
1936

TdTomato $^{-}$cells was corrected for the presence of non-MSN cells. Data were quantified as follows: $\left(\right.$ TdTomato $^{+}: \Delta \mathrm{FosB}^{+}$neurons $\times$ 100\%)/(total TdTomato $^{+}$neurons) and (TdTomato ${ }^{-}: \Delta$ FosB $^{+}$ neurons $\times 95 \%) /\left(\right.$ total TdTomato $^{-}$neurons).

CSDS and behavioral evaluations

CSDS was performed as previously described [32] (see Supplementary Material and Methods for full details).

Two-bottle sucrose preference test

Sucrose preference tests were performed as previously described [32] (see Supplementary Material and Methods for full details).

Open-field test

Open-field tests were performed as previously described [32] (see Supplementary Material and Methods for full details).

Stereotaxic surgery

Overexpression of mCREB or $\triangle$ JunD specifically in the NAc was achieved by injecting an adeno-associated virus (rAAV2) vector expressing $m C R E B$, or $\triangle J u n D[16,36]$. The $\triangle J u n D$ virus preparation was spiked with rAAV2-GFP $(1: 10)$ to allow for assessment of injection site. Control mice were injected with a rAAV2-GFP. IntraNAc injections were performed as previously described [37] (see Supplementary Material and Methods for full details).

Dendritic spine analysis

Dendritic spine analysis was performed as previously described [38] (see Supplementary Material and Methods for full details).

Statistical analysis

All data are presented as mean \pm SEM. Two group comparisons were performed by two-tailed Student's $t$-test. Assessment of effects in experiments involving several conditions was performed using one-, two-, or three-way analysis of variance (ANOVA), with repeated measures where applicable, followed, when appropriate, by Tukey HSD post hoc tests, adjusting for multiple comparisons. For all cases, a $P$-value $<0.05$ was considered significant. See figure legends for statistical details of individual experiments, including statistical tests used, $t, P, F$-values, and number of subjects or samples tested.

\section{RESULTS}

VWR prior to CSDS prevents development of social avoidance and anhedonia

To test if VWR prevents the development of depression-like behaviors during CSDS, we used a rodent model in which 10week-old male C57BL/6J mice were single housed without (sedentary) or with (VWR) free access to running wheels for $21 \mathrm{~d}$ before being subjected to $10 \mathrm{~d}$ of CSDS (Fig. 1a). By the end of the second week, mice with wheel access were consistently running approximately $7 \mathrm{~km}$ per day (Fig. 1b). VWR lowered body weight gain, increased food and water intake, but did not affect basal sucrose preference (Figures S1a-e).

After $21 \mathrm{~d}$ of VWR or sedentary housing, mice were further subdivided in mice that remained unexposed to aggressor mice (i.e., undefeated controls) or mice that were subjected to CSDS (i.e., defeated), a paradigm that in our hands reliably induces depression-like behavior [16, 17, 32]. In brief, social defeat was induced by daily 10-min exposure to an aggressor for $10 \mathrm{~d}$, with the remainder of each day spent in sensory contact. Control mice were handled daily and spent each day in sensory contact with another experimental mouse (Fig. 1a). On day 11, $24 \mathrm{~h}$ after the last social defeat episode, all defeated and control mice underwent a social interaction test, where mice are placed in an openfield set-up containing a small cage containing an unfamiliar mouse (Figure S2a). The amount of time spent interacting with or avoiding the unfamiliar mouse serves as a readout for social avoidance, which correlates well with several other depressionrelated behavioral abnormalities [17]. Two-way ANOVA analysis revealed a main effect of CSDS on social behavior (Figs. 1c, d). Additional analysis, using an a posteriori $t$-test, revealed that defeated VWR mice showed a reduced propensity to develop social avoidance compared with defeated sedentary mice (Figs. 1c, d), suggesting that VWR prior to CSDS decreases susceptibility to subsequent social defeat. In support of this, analysis of social interaction ratios, a measure used to segregate resilient and susceptible populations [17], revealed that VWR increased the proportion of resilient mice (Figs. 1e, f). Differences in social behavior between the defeated sedentary and defeated VWR mice could not be explained by differences in locomotor activity during the social interaction test (Figure S2b), nor by differences in stress exposure, as indicated by similar changes in body weight, minor wounds sustained and stress-induced polydipsia during night 11 (Figures S2c-e). We then used an open-field test to measure locomotor activity and the amount of time spent in the center or periphery of an open-field area, as a readout for anxiety-like behavior. All defeated mice showed reduced locomotor activity and increased anxiety-like behavior, as indicated by less center zone entries, compared with undefeated controls (Figures S2f and g). Sucrose preference is measured by simultaneously offering two bottles, one with a sugar dilution and one with normal water. A decrease in sucrose preference is another measure of depressionlike behavior, which is indicative of anhedonia [15]. Defeated sedentary mice showed a significant decrease in sucrose preference compared with pre-social defeat levels, whereas both defeated VWR mice and undefeated controls did not (Fig. 1f).

Spatial and temporal aspects of VWR induction of $\triangle F o s B$ in the NAc

To assess the spatial induction of $\Delta \mathrm{FosB}$ in the striatum, wild-type mice were housed without or with free access to running wheels for $14 \mathrm{~d}$ (Figures S3a and b). Quantitative immunohistochemistry was subsequently used to identify $\Delta$ FosB-positive neurons in striatal regions (Fig. 2a). VWR mice had more $\triangle$ FosB-positive neurons than sedentary mice in the NAc core, NAc shell, and the dorsomedial striatum, whereas $\Delta$ FosB-positive neurons in the dorsolateral striatum were relatively less abundant and similar between experimental groups (Figs. 2b, c).

To study the temporal dynamics of $\triangle$ FosB induction in the NAC during VWR, we performed western blot analysis on NAC dissections containing both core and shell subregions of the NAc (Figure S4a). Using this approach, we confirmed that VWR promotes accumulation of $\triangle$ FosB in the NAc (Fig. 2d). Furthermore, cage enrichment controls (i.e., mice housed with a blocked running wheel) showed no significant induction of $\triangle F o s B$ in the NAc compared with sedentary mice, suggesting that it was the VWR, not the presence of a running wheel, which resulted in accumulation of $\triangle$ FosB in the NAc (Fig. 2d). Finally, we found that $14 \mathrm{~d}$, or longer, of VWR, but not $7 \mathrm{~d}$, resulted in significant accumulation of $\triangle \mathrm{FosB}$ in the NAc compared with sedentary controls (Figures S4b-d).

Prior indirect analysis in rats, using dynorphin expression as a marker for D1-MSNs and enkephalin expression as a marker for D2-MSNs, suggested that VWR induces $\triangle$ FosB preferentially in D1MSNs of the NAc core [30], although this has heretofore not been examined directly. To examine this directly, we made use of a mouse model in which TdTomato expression is driven by the Drd1a promoter [39], with the presence of TdTomato $\left(\right.$ TdTomato $^{+}$) defining D1-MSNs and the absence of TdTomato (TdTomato ${ }^{-}$) likely defining D2-MSNs [40]. Cell-specific induction of $\triangle$ FosB in the NAc was assessed following $14 \mathrm{~d}$ of VWR and 1 day of wheel blockade (Figures S3a and $\mathrm{c}$ ). Immunohistochemical analysis determined that VWR increased $\triangle$ FosB in both TdTomato $^{+}$and TdTomato $^{-}$MSNs of the NAc core (Figs. 2e, f). In contrast, VWR 
A

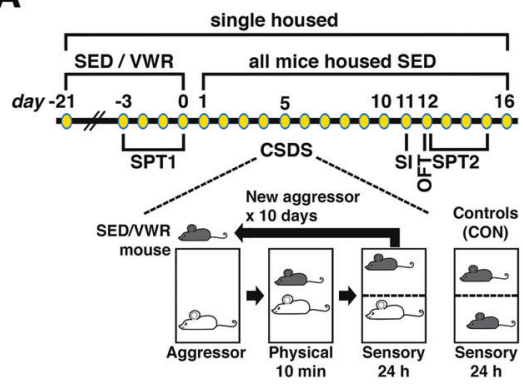

D

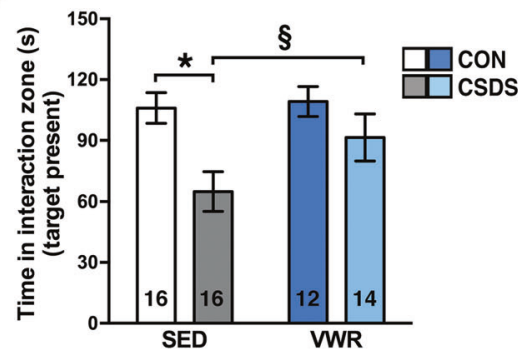

$\mathbf{F}$

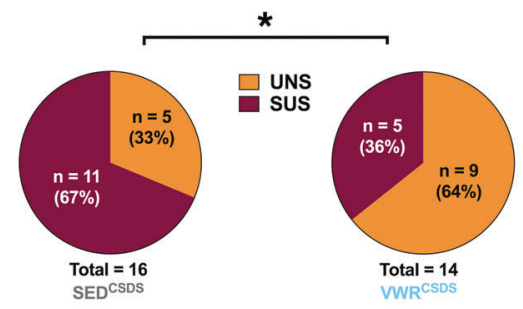

B

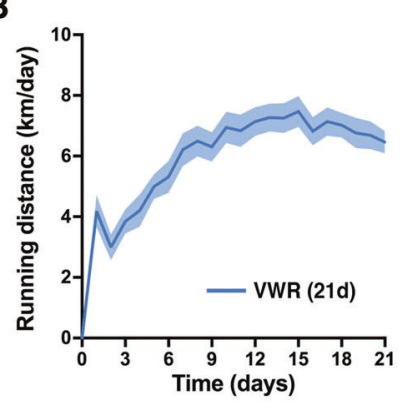

E

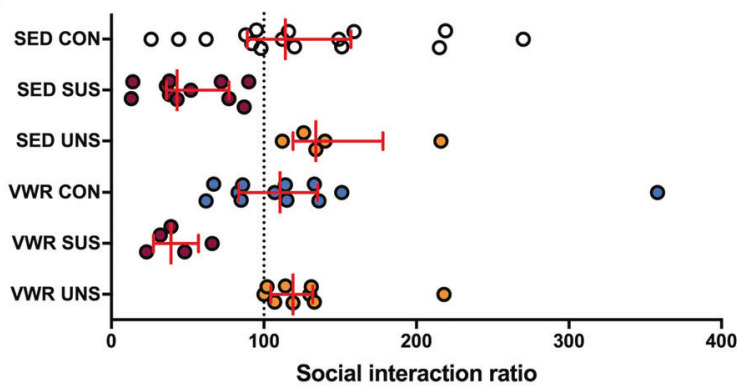

G

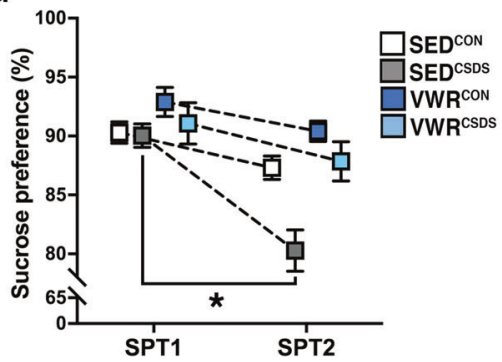

Fig. 1 VWR prior to CSDS prevents development of social avoidance and anhedonia. a Experimental timeline of sedentary (SED) or voluntary wheel running (VWR) housing for $21 \mathrm{~d}$, followed by chronic social defeat stress (CSDS) for $10 \mathrm{~d}$ and behavioral tests. SPT sucrose preference test, SI social interaction test, OFT open-field test. Control (CON) mice remained undefeated. b Daily VWR distance ( $n=26$; main effect of time, $F_{20,500}=17.1, P<0.00001$; one-way ANOVA with repeated measures followed by Tukey's HSD test). c Videotracking data of ambulatory movement from control (SED ${ }^{C O N}$, VWR ${ }^{C O N}$ ) and CSDS (SED ${ }^{C S D S}, V^{2} R^{C S D S}$ ) mice in the presence of a social target during the SI test. d Effects of VWR for $21 \mathrm{~d}$ prior to CSDS on the development of social avoidance during CSDS, measured on day 11 (main effect of $C S D S, F_{1,54}=9.86, P=$ 0.003 , two-way ANOVA; $t_{1,30}=3.35,{ }^{*} P=0.002$ versus SED ${ }^{\text {CON }} ; t_{1,28}=2.31,{ }^{5} P=0.03$ versus SED ${ }^{\text {CSDS }}$, a posteriori t-test. e Horizontal scatterplot depicting the distribution of interaction ratios for CON, susceptible (SUS) and unsusceptible (UNS) SED and VWR subgroups (error bars represent median \pm interquartile range). f Proportion of SUS and UNS mice in SED ${ }^{C S D S}$ and VWR ${ }^{C S D S}$ cohorts based on social behavior on day $11 ;{ }^{*} P=0.037$, susceptibility ratio SED ${ }^{C S D S}$ versus VWR ${ }^{C S D S}$, Pearson chi-squared test. $g$ VWR for $21 \mathrm{~d}$ prior to CSDS prevented development of anhedonia during CSDS (time $x$ housing interaction, $F_{33} 5_{4}=3.04, P=0.037 ; S^{C O N}{ }^{C O N}, P=0.71$, SPT1 versus SPT2; VWR ${ }^{\mathrm{CON}}, P=0.80, S P T 1$ versus SPT2; SED ${ }^{C S D S},{ }^{*} P=0.0002$, SPT1 versus SPT2; VWR CSOS,$P=0.37$, SPT1 versus SPT2; two-way ANOVA with repeated measures followed by Tukey's HSD test). $\mathrm{SED}^{\mathrm{CON}}=16, \mathrm{SED}^{\mathrm{CSDS}}=16, \mathrm{VWR}^{\mathrm{CON}}=12, \mathrm{VWR}^{\prime}{ }^{\mathrm{CSDS}}=14$

induction of $\triangle$ FosB predominantly occurred in TdTomato $^{+}$MSNs of the NAc shell (Figs. 2e, f).

CREB is required for VWR induction of $\triangle \mathrm{FosB}$ in NAC

We next investigated upstream signaling pathways mediating VWR induction of $\triangle F$ osB in NAc. Based on studies using chronic cocaine treatment [37], we investigated if serum response factor (SRF) and CAMP response element-binding protein (CREB) might be involved in VWR induction of NAc $\triangle F$ osB. Western blot analysis of whole NAc dissections revealed similar phosphorylation of CREB at serine $133\left(\mathrm{Ser}^{133}\right)$ and of SRF at serine $103\left(\mathrm{Ser}^{103}\right)$ in sedentary and VWR mice sacrificed during the light phase, when mice are resting (Figures S5a-c). In contrast, when sedentary and VWR mice were sacrificed during the early dark phase, when mice are active, VWR was associated with increased CREB $\left(\mathrm{Ser}^{133}\right)$ phosphorylation compared with sedentary controls. In addition, CREB $\left(\mathrm{Ser}^{133}\right)$ phosphorylation correlated strongly with the amount of VWR performed just before brains were isolated (Figures S5d and f). There was no effect of VWR on SRF $\left(\mathrm{Ser}^{103}\right)$ phosphorylation (Figures S5d, g, and h).

To directly test if CREB signaling is necessary for VWR induction of NAC $\triangle$ FosB, we virally overexpressed a dominant-negative mutant protein that functionally inhibits endogenous CREB (mCREB) [6] or the fluorescent reporter green fluorescent protein (GFP), as a control, in the NAC of sedentary and VWR mice (Figures S5i-I). Overexpression of mCREB in the NAc prevented VWR induction of $\triangle$ FosB in the NAC (Fig. 2g).

VWR modulates dendritic morphology of NAc MSNs Dendritic spines can be divided into three distinct functional subclasses that include immature stubby spines, which have a clear spine head but lack a neck, and neck-bearing immature thin and mature mushroom spines where the size of the head region (larger in mushroom spines) is among the primary distinguishing 
A

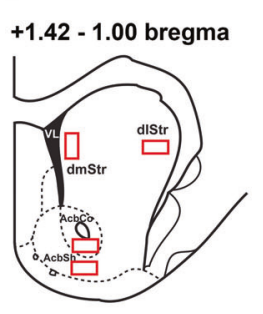

B

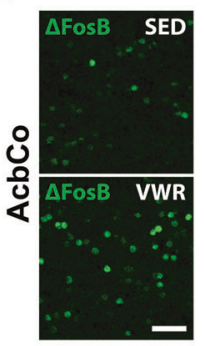

C

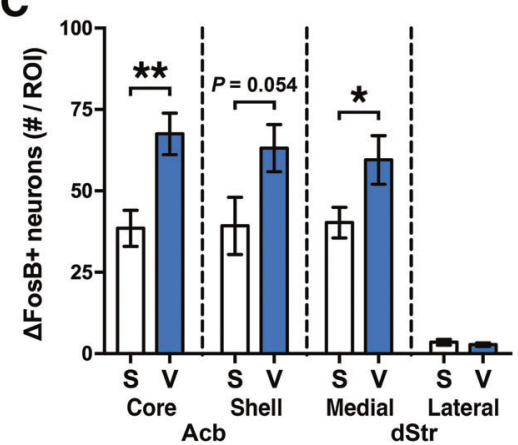

D
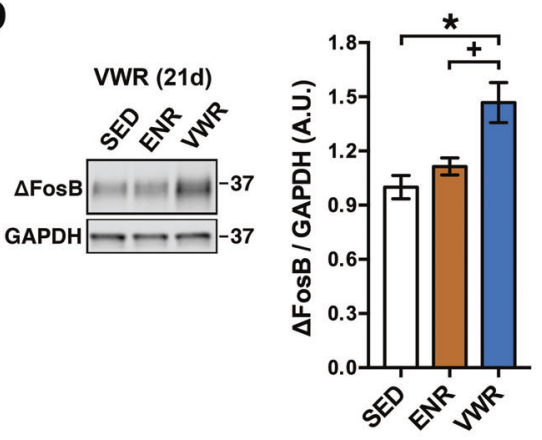
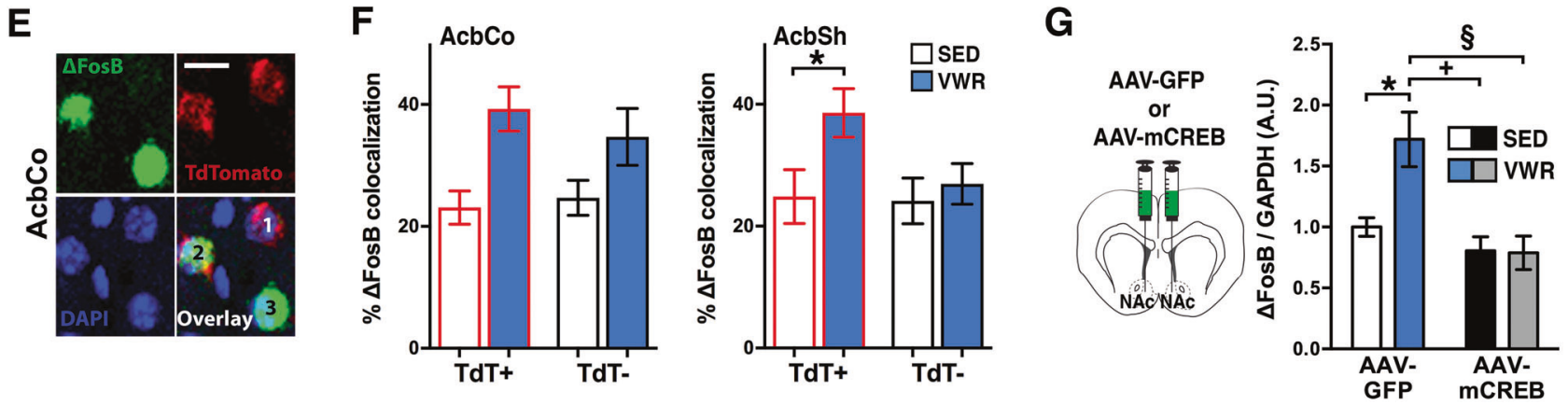

Fig. 2 VWR induction of $\triangle F$ FosB in NAc. a Coronal cartoon showing NAc core (AcbCo) and shell (AcbSh), and dorsomedial (dmStr) and dorsolateral (dIStr) striatum regions of interest (ROI; red) used for quantification of $\Delta \mathrm{FosB}^{+}$neurons. VL lateral ventricle. $\mathbf{b}$ Representative single channel confocal micrographs of $\Delta \mathrm{FosB}^{+}$(green) neurons in AcbCo of sedentary (SED) and voluntary wheel running (VWR) mice after $14 \mathrm{~d}$ of VWR (scale bar, $60 \mu \mathrm{m}$ ). c Quantification of $\Delta \mathrm{FosB}^{+}$neurons in AcbCo, AcbSh, dmStr and dIStr ROIs in SED (S) and VWR (V) mice ( $\mathrm{n}=8$ / group; $t_{1,14}=3.42,{ }^{*} P=0.004 ; t_{1,14}=2.09, P=0.054 ; t_{1,14}=2.19,{ }^{*} P=0.046 ; t_{1,14}=0.72, P=0.49$, respectively; $t$-test). d Representative protein blots of the 35-37kd $\Delta$ FosB isoforms (left) and quantification of $\triangle$ FosB protein levels (right) in whole NAc dissections of mice after $21 \mathrm{~d}$ of SED, cage enrichment (ENR), or VWR housing $\left(n=15-17 ; F_{2,44}=9.08, P=0.0005 ;{ }^{*} P=0.0007\right.$ versus SED, ${ }^{+} P=0.01$ versus ENR; one-way ANOVA followed by Tukey's HSD test). e Representative single channel and overlay confocal micrographs of $\Delta$ FosB (green), TdTomato (red), and DAPI (blue). 1: TdTomato $^{+}: \Delta$ FosB $^{-}$medium spiny neuron (MSN); 2: TdTomato $^{+}: \Delta$ FosB $^{+}$MSN; 3: TdTomato ${ }^{-}: \Delta$ FosB $^{+}$MSN (scale bar, $15 \mu$ m). f Quantification of the percentage of the TdTomato $^{+}(\mathrm{TdT}+)$ and TdTomato ${ }^{-}$(TdT-) MSNs that were also $\Delta$ FosB $^{+}$in the AcbCo (left; main effect of $V W R, F_{1,18}=12.37, P=0.003$ ) or the AcbSh (right; main effect of $V W R, F_{1,18}=4.54, P=0.047 ;$ two-way ANOVA; $t_{1,9}=2.32$, $* P=0.046$ versus SED TdT+; a posteriori $t$-test) of SED and VWR ( $14 \mathrm{~d}$ ) Drd1a-Tdtomato mice $(n=5-6 /$ group). g Bilateral intra-accumbal administration of AAVGFP or AAV-mCREB. Overexpression of mCREB specifically in the NAc during VWR for $21 \mathrm{~d}$ prevented VWR induction of $\triangle$ FosB in whole NAC dissections (VWR x AAV interaction, $F_{1,12}=6.12, P=0.03 ;{ }^{*} P=0.04$ versus SED ${ }^{\mathrm{GFP}} ;{ }^{+} P=0.004$ versus SED ${ }^{\mathrm{mCREB}} ;{ }^{\S} P=0.004$ versus $\mathrm{VWR}^{\mathrm{S} C R E B}$; two-way ANOVA followed by Tukey's HSD test; $n=5-6 /$ group)

features of these spine types [41]. Short-term overexpression of $\triangle \mathrm{FosB}$ in NAc increases immature, predominantly stubby, spines on MSNs [42]. In addition, $\triangle$ FosB expression is associated with the formation and/or the maintenance of dendritic spines on NAC MSNs after chronic cocaine treatment [43]. How VWR modulates NAc spine morphogenesis in mice remains unknown. To assess this, we infused HSV-GFP into the NAc of VWR mice and sedentary controls. After $21 \mathrm{~d}$ of VWR, total spine density in NAc MSNs showed an increased trend in VWR mice compared with sedentary controls (Figs. 3a, b). This increase was driven by a significant induction of immature thin spines (Figs. 3c, d).

\section{Transcriptional blockade of NAc $\triangle$ FosB during VWR reinstates} susceptibility to CSDS

To test the functional consequences of VWR induction of NAC $\triangle \mathrm{FosB}$, we virally overexpressed a dominant-negative JunD mutant protein $(\triangle$ JunD) that antagonizes $\Delta$ FosB function [16], or GFP as a control, in the NAc (Fig. 4a; S6a and b). Transcriptional silencing of $\triangle F$ osB in NAc has no effect on baseline measures of locomotor activity and anxiety-like behavior [16]. Wild-type C57BL/6J mice overexpressing $\triangle \mathrm{JunD}$ or GFP in the NAc were given free access to running wheels for $21 \mathrm{~d}$ before being subjected to $10 \mathrm{~d}$ of CSDS (Fig. 4a). Sedentary undefeated and defeated C57BL/6J mice served as additional controls (Fig. 4a). Mice overexpressing GFP or $\triangle J$ unD specifically in the NAC demonstrated normal VWR behavior, although daily and cumulative running distances were slightly lower in mice overexpressing $\triangle$ JunD (Figure S6c). Overexpression of $\triangle \mathrm{JunD}$ in the NAc did not affect metabolic responding to VWR or preference for a $1 \%$ sucrose solution (Figures S6d-h).

During the social interaction test on day 11 , and confirming our previous results, VWR mice overexpressing GFP in the NAc showed reduced propensity to develop social avoidance and anhedonia compared with defeated sedentary mice (Figs. 4b, c). In contrast, mice with NAc-specific transcriptional blockade of $\triangle$ FosB during VWR developed social avoidance and anhedonia, indicative of reinstated susceptibility to CSDS (Figs. 4b, c). Differences in social behavior between the defeated mice overexpressing either GFP or $\triangle \mathrm{JunD}$ in the NAc could not be explained by altered locomotor activity during the social interaction test (Figure S7a), nor by differences in exposure to social defeat stress, as indicated by similar changes in body weight, minor wounds sustained, and stress-induced polydipsia during night 11 (Figures S7b-d). All defeated mice showed hypoactivity and increased anxiety-like behavior compared with undefeated controls in the open-field test (Figures S7e and f).

VWR following CSDS ameliorates CSDS-induced social avoidance CSDS-induced social avoidance is maintained over time [17]. Therefore, we assessed if VWR following CSDS was able to restore 
A

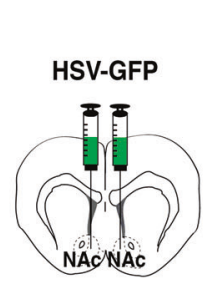

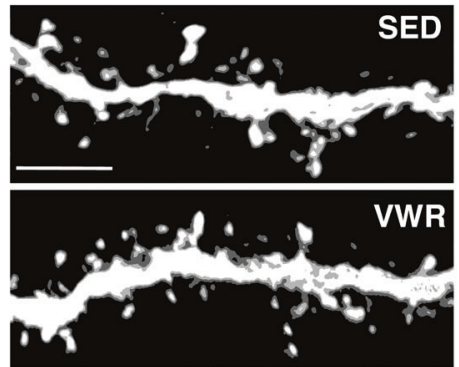

B

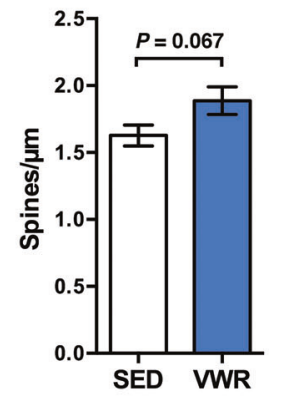

C

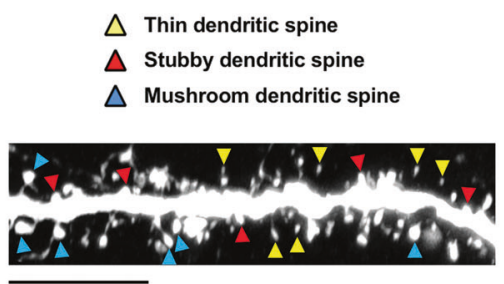

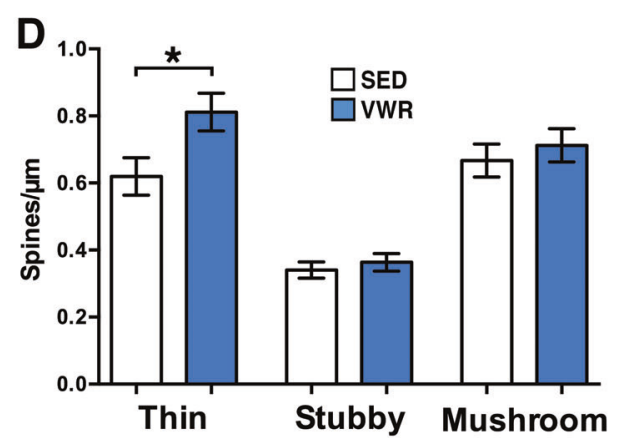

Fig. 3 Effects of VWR on NAc MSN spine morphology. a Bilateral intra-accumbal administration of HSV-GFP (left) and high-magnification images showing a dendritic segment illustrating different spine subtypes following sedentary (SED) and voluntary wheel running (VWR) housing conditions for $21 \mathrm{~d}$ (right). MSNs overexpressed HSV-GFP, shown in black and white (scale bar, $5 \mu \mathrm{m}$ ). $\mathbf{b}$ VWR tended to increase total spine density in NAc MSNs of VWR mice ( $n=14$ cells in three mice) compared with SED mice $\left(n=11\right.$ cells in three mice; $t_{1,23}=1.92, P=0.067$; $t$-test). c High-magnification image showing a dendritic segment from a SED mouse. Different spine subclasses are noted (scale bar, $5 \mu \mathrm{m}$ ). $\mathbf{d}$ VWR increased the density of thin, but not stubby or mushroom, spines on NAc MSN dendrites (main effect of $V W R, F_{1,69}=5.31, P=0.024$; main effect of spine subtype, $F_{2,69}=38.48, P<0.000001 ;{ }^{*} P<0.05$ versus SED; two-way ANOVA followed by Tukey's HSD test)

A

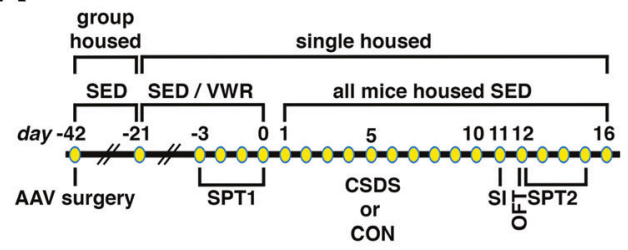

B

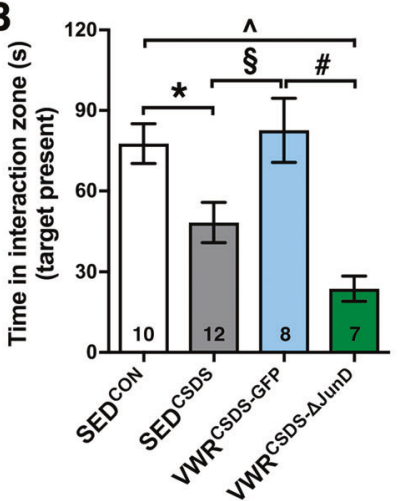

C

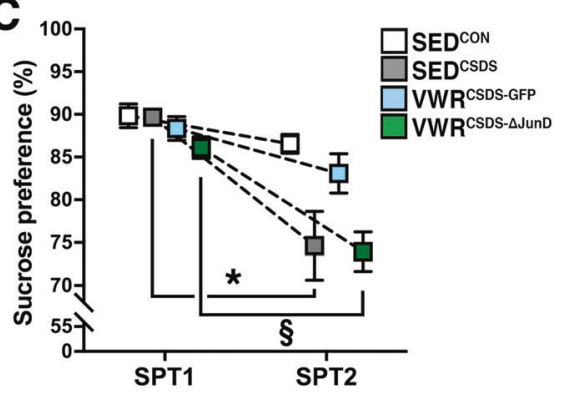

Fig. 4 Transcriptional blockade of NAc $\triangle$ FosB during VWR reinstates susceptibility to CSDS. a Experimental timeline of intra-accumbal viralmediated gene transfer and recovery for $21 \mathrm{~d}$, followed by sedentary (SED) or voluntary wheel running (VWR) housing for $21 \mathrm{~d}$, chronic social defeat stress (CSDS) for $10 \mathrm{~d}$, and behavioral tests. SPT sucrose preference test, SI social interaction test, OFT open-field test. Control (CON) mice remained undefeated. b VWR for $21 \mathrm{~d}$ prior to CSDS protected VWR ${ }^{C S D S-G F P}$ mice from developing social avoidance during CSDS, whereas NAc-specific overexpression of $\triangle$ JunD in VWR ${ }^{\text {CSDS- } \triangle \text { JunD }}$ mice reinstated susceptibility $\left(F_{3,33}=9.36, P=0.0001, * P=0.049\right.$ versus $\mathrm{SED}^{\mathrm{CON}} ;{ }^{\S} P=0.027$ versus VWR ${ }^{\mathrm{CSDS}-G F P} ;{ }^{\wedge} P=0.0009$ versus SED ${ }^{\mathrm{CON}} ;{ }^{\#} P=0.0006$ versus VWR ${ }^{\mathrm{CSDS}} \mathrm{C}$-GF ; one-way ANOVA followed by Tukey's HSD test). c VWR for $21 \mathrm{~d}$ prior to CSDS protected VWR CSDS-GFP' mice from developing anhedonia during CSDS, whereas NAc-Specific overexpression of $\triangle$ JunD in VWR ${ }^{\text {CSDS- } \triangle \text { JunD }}$ mice reinstated susceptibility (time $\mathrm{x}$ housing interaction, $F_{3,33}=4.78, P=0.007 ; \mathrm{SED}^{\mathrm{CON}}, P=0.92$, SPT1 versus SPT2; SED ${ }^{\text {CSDS }, ~} * P=0.0002$, SPT1 versus SPT2; VWR ${ }^{\text {CSDS-GFP }} P=0.88$, SPT1 versus SPT2; ${ }_{\text {VWR }}{ }^{\text {CSDS- } \triangle \text { JunD }}{ }^{\S} P=0.01$, SPT1 versus SPT2; two-way ANOVA with repeated measures followed by Tukey's HSD test). SED ${ }^{\text {CON }}=10$, SED $^{\text {CSDS }}$ $=12, \mathrm{VWR}^{\mathrm{CSDS}-\mathrm{GFP}}=8, \mathrm{VWR}^{\mathrm{CSDS}-\triangle \mathrm{J} \text { UnD }}=7$

aberrant social behavior in susceptible mice (Fig. 5a). When examined $24 \mathrm{~h}$ after the last social defeat ("day 11 "), 10 out of 20 defeated mice were labeled "susceptible" based on their social interaction scores (data not shown). This percentage is representative for C57BL/6J mice [17]. As expected, susceptible mice showed social avoidance compared with undefeated controls (Fig. 5b). Subsequently, a subset of the susceptible mice was given free access to running wheels after day 11 , whereas the remainder of susceptible mice remained sedentary. When examined $42 \mathrm{~d}$ after the last defeat ("day $\left.53^{\prime \prime}\right)$, susceptible mice that had been running showed social behavior similar to the level of undefeated controls, whereas sedentary susceptible mice still displayed social avoidance (Figs. 5b, c). Differences in social behavior between the susceptible mice housed either sedentary or with running wheels 
A

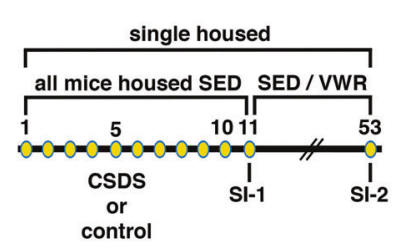

B

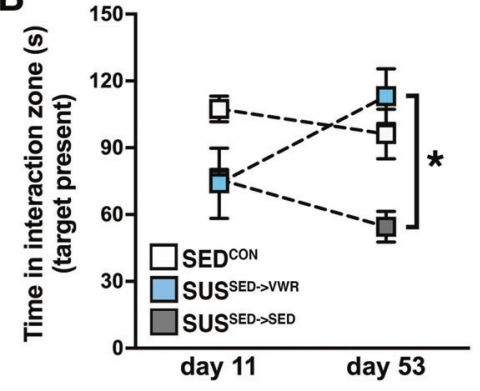

C

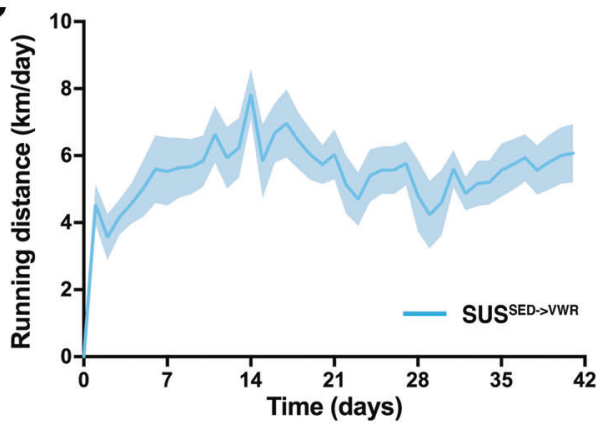

D

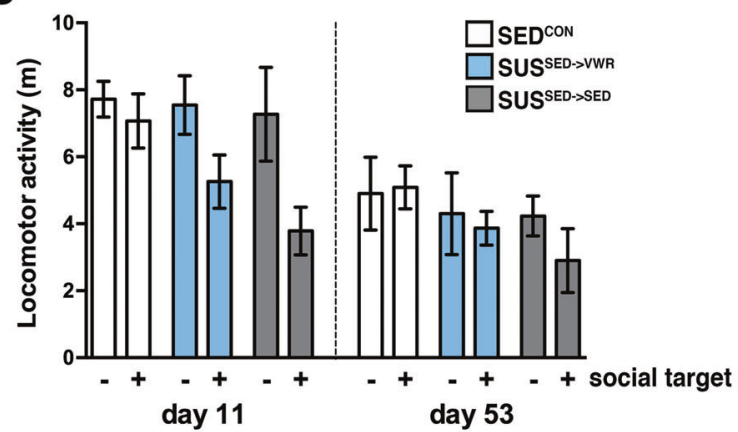

E

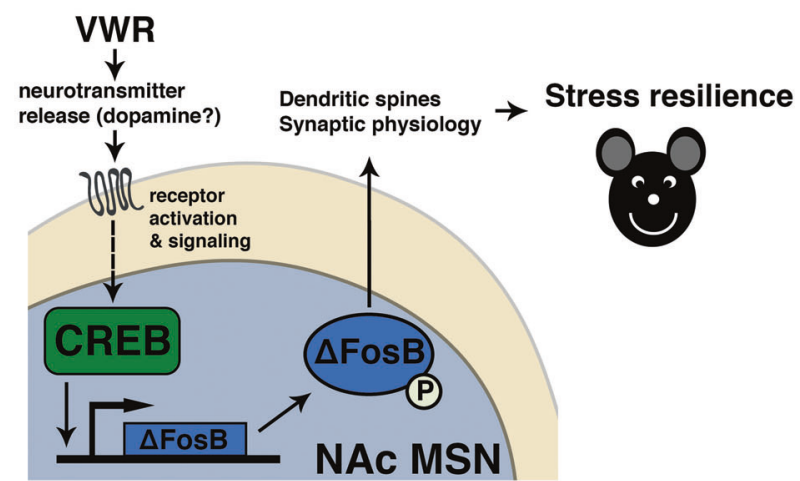

Fig. 5 VWR following CSDS ameliorates CSDS-induced social avoidance. a Experimental timeline of chronic social defeat stress (CSDS) or control (no CSDS) housing for $10 \mathrm{~d}$, followed by social interaction test 1 (SI-1) on day 11, sedentary (SED) or voluntary wheel running (VWR)

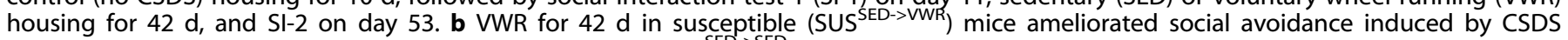
compared with susceptible mice that remained sedentary (SUS ${ }^{S E D-} \rightarrow S E D$ ), measured on day 11 and day 53 (time $x$ housing interaction, $F_{2,17}=$ $3.88, P=0.041 ;{ }^{*} P=0.32$, day 53 SUS $^{\text {SED } \rightarrow V W R}$ versus day 53 SUS $^{\text {SED- }>\text { SED }}$; two-way ANOVA with repeated measures followed by Tukey's HSD test). c Daily running distance of SUS ${ }^{S E D->V W R}$ mice (main effect of time, $F_{40,200}^{\prime}=2.16, P=0.0003$; one-way ANOVA with repeated measures). d Locomotor activity during SI-1 (day 11) and SI-2 (day 53) without $(-)$ or with (+) presence of social target (main effect of treatment, $F_{2,68}=3.30$, $P=0.04$; main effect of social target, $F_{1,68}=5.72, P=0.02$; main effect of $S I, F_{1,68}=17.43, P=0.00009$ ). e Schematic model depicting CREBdependent induction of $\triangle$ FosB in NAC MSNs and physiological processes that may underlie VWR-mediated stress resilience. CON ${ }^{\mathrm{SED}}=10$, $\mathrm{SUS}^{\mathrm{SED}->\mathrm{VWR}}=6, \mathrm{SUS}^{\mathrm{SED}-\mathrm{SED}}=4$

could not be explained by altered locomotor activity during the social interaction tests (Fig. 5d).

\section{DISCUSSION}

Physical exercise has well-documented beneficial effects on stressrelated mental disorders, but the underlying mechanisms remain incompletely understood. Here, we demonstrate that 21 days of VWR prevents the development of social avoidance and anhedonia during CSDS, whereas anxiety-related behaviors measured in the open-field test remained unchanged. Furthermore, using a combination of behavioral, molecular, and viral gene transfer approaches, we demonstrate that VWR induction of $\triangle$ FosB in the NAc subregions occurs in specific MSN populations, VWR is associated with changes in MSN dendritic morphology, and that functional blockade of NAc $\triangle$ FosB during VWR reinstated susceptibility to CSDS. These data suggest that VWR induction of NAc $\triangle$ FosB contributes to the pro-resilient effects of VWR observed in this study (Fig. 5e). Finally, 42 days of VWR ameliorated CSDS-induced social avoidance behavior, indicative of antidepressant potential of VWR.

Although both the NAc, as well as $\triangle$ FosB have been heavily implicated in stress responses and mood disorders [7], our study is the first attempt to directly link NAc $\triangle \mathrm{FosB}$ to the pro-resilient effects of VWR. Mechanistic studies in rodents, investigating the antidepressant potential of VWR, have previously indicated the involvement of several brain nuclei, most notably the hippocampus and the basolateral amygdala [22, 44-46]. Our findings now add the NAc to the brain circuitry involved in the beneficial effects of VWR on stress-related behavior. This is in line with the role of the ventral striatal motor-limbic interface that integrates emotional information from several brain regions, including the basolateral amygdala, and translates such information into behaviorally relevant outputs [9].

VWR induction of $\triangle$ FosB occurred equally in D1- and D2-MSNs in the NAc core, yet was selective for D1-MSNs in the NAc shell. This $\triangle$ FosB induction pattern in the NAc subregions resembles the induction pattern observed in response to 10-min optogenetic activation of ventral tegmental area neurons on 5 consecutive days [18], suggesting that activation of dopaminergic neurons in the ventral tegmental area during VWR, and subsequent activation of dopamine receptors in the NAc, is an important factor that drives accumulation of NAc $\triangle F$ osB. Although activation of dopaminergic ventral tegmental area neurons during VWR has to date not been measured directly, observations that the ventral tegmental area can modulate VWR behavior [47, 48], and that VWR induces plasticity along the ventral tegmental area-striatum axis [27, 29], support this possibility.

The VWR induction pattern of NAc $\triangle$ FosB observed in this study differs from the induction pattern observed after $28 \mathrm{~d}$ of juvenile environmental enrichment or $10 \mathrm{~d}$ of a $10 \%$ sugar dilution, naturally rewarding conditions that both show equal induction of $\triangle$ FosB in D1- and D2-MSNs in the NAc subregions [18]. It should, however, be noted that VWR transiently increases plasma corticosterone levels during the first 3 weeks of VWR and is associated with profound adaptations along the hypothalamic-pituitary-adrenal axis [22,49]. Thus, VWR should be considered a physiological stressor, especially during the initial 
weeks of VWR. Furthermore, VWR animals and their sedentary controls are commonly single housed to accurately measure VWR behavior and its metabolic consequences. Prolonged isolation, 8 weeks or longer, can increase susceptibility to stress in rodents $[16,50]$. In this study, we did not observe anhedonia in any of our experiments following the 3 weeks of single housing prior to CSDS. This suggests that this duration is not sufficient to induce a depressive-like state. However, we cannot rule out that the social isolation primed susceptibility to CSDS, an effect that could be prevented by VWR. In this light, it will be interesting to investigate if VWR retains its pro-resilient capacity in group-housed animals.

Following CSDS, resilient mice show selective induction of $\triangle$ FosB in NAc D1-MSNs, whereas susceptible mice show selective induction of $\triangle$ FosB in D2-MSNs [18]. Thus, equal induction in D1MSNs and D2-MSNs in NAc core, but selective induction in D1MSNs in NAc shell, after $14 \mathrm{~d}$ of VWR likely results from a temporal interplay between reward- and stress-related brain circuitries. Further work is needed to identify the role of the two MSN subtypes, the different striatal subregions, as well as temporal NAc neurotransmitter dynamics in mediating the beneficial effects of VWR on stress-related behavior. Potential neurotransmitters involved are brain-derived neurotrophic factor, dopamine, and lactate, as all of these factors are centrally modulated by physical exercise and involved in the modulation of depressive-like behavior [22, 51-55].

What are the potential mechanisms underlying the regulation of stress resilience by VWR? We observed a trend for an increase in total dendritic spine density on NAc MSNs following VWR, resulting from an increase in thin, but not stubby or mushroom, spines. Although we have not directly investigated the functional consequences of these spine type-specific alterations in NAc MSNs following VWR, $\triangle$ FosB is known to modulate synaptic properties of NAc MSNs and subsequent reward-related behavior [42, 56, 57].

Susceptible, but not resilient, mice demonstrate an increase in immature stubby spines on NAc MSNs in response to CSDS [58, 59]. Similarly, short-term overexpression of $\triangle F o s B$ in $N A C$ predominantly increases stubby spines on D1-MSNs [42]. However, these studies did not reveal an increase in NAc thin spines in resilient mice or following short-term overexpression of $\Delta$ FosB. In contrast, early (i.e., $4 \mathrm{~h}$ ) withdrawal from cocaine is associated with an increase in thin, but not stubby or mushroom, spines in the NAc shell, but not the core, subregion [60]. These observations suggest that the specific increase in thin spines observed in this study could result from the time when the VWR mice were euthanized, that is, during the light phase when mice are resting (i.e., voluntary short-term withdrawal from VWR). Similar to our observations in mice, a recent study in female Wistar rats demonstrated that 3 weeks of VWR is associated with increased total spine density, and a relative increase and decrease in thin and stubby spines, respectively [61]. Collectively, these studies provide strong rationale to investigate how VWR alters synaptic maturation and function in the NAc, and to identify the functional consequences of altered VWR-associated NAc MSN spine formation on stress resilience. Such studies should take into account the duration of and/or withdrawal from VWR as well as functional differences between the NAc subregions and MSN subtypes.

Full understanding of the neurobiological adaptations during physical exercise is critical in order to develop rational and optimal treatment strategies for patients suffering from stress-related disorders. Furthermore, such understanding can aid in the prevention of stress-related disorders in healthy subjects. Our identification of $\triangle \mathrm{FosB}$ in the NAc as a likely contributor to the greater stress resilience following VWR provides new insight into the nature of VWR-mediated adaptations in the NAc. The possible relevance of our results to human psychiatry is suggested by the observations that high physical activity modulates dopaminergic neurotransmission in the striatum of human subjects $[62,63]$. This neuronal pathway may therefore represent a target for the development of therapeutic treatments for stress-associated mental illnesses based on physical exercise.

\section{ACKNOWLEDGEMENTS}

We are grateful to Christopher Cahill (Joslin Diabetes Center microscopy core) and Dr. Peter Hamilton (Mount Sinai) for assistance with imaging studies, and members of the Goodyear lab for helpful comments throughout the course of this project. This work was supported by National Institutes of Health (NIH) grants R01-DK-101043 and R01-DK-099511 to LJG; NIH grant 5P30-DK-36836 to the Diabetes Research Center, Joslin Diabetes Center; and a National Institute of Mental Health grant R01-MH051399 to EJN.; JDM was supported by an American Diabetes Association Mentor-based Award to LG (7-12-MN-22).

\section{ADDITIONAL INFORMATION}

Supplementary Information accompanies this paper at (https://doi.org/10.1038/ s41386-018-0103-z)

Competing interests: The authors declare no competing interests.

Publisher's note: Springer Nature remains neutral with regard to jurisdictional claims in published maps and institutional affiliations.

\section{REFERENCES}

1. Greenberg PE, Kessler RC, Birnbaum HG, Leong SA, Lowe SW, Berglund PA, et al. The economic burden of depression in the United States: how did it change between 1990 and 2000? J Clin Psychiatry. 2003;64:1465-75.

2. Kessler RC, Berglund P, Demler O, Jin R, Merikangas KR, Walters EE. Lifetime prevalence and age-of-onset distributions of DSM-IV disorders in the National Comorbidity Survey Replication. Arch Gen Psychiatry. 2005;62:593-602.

3. Russo SJ, Murrough JW, Han MH, Charney DS, Nestler EJ. Neurobiology of resilience. Nat Neurosci. 2012;15:1475-84.

4. Feder A, Nestler EJ, Charney DS. Psychobiology and molecular genetics of resilience. Nat Rev Neurosci. 2009;10:446-57.

5. Hope BT, Nye HE, Kelz MB, Self DW, ladarola MJ, Nakabeppu Y, et al. Induction of a long-lasting AP-1 complex composed of altered Fos-like proteins in brain by chronic cocaine and other chronic treatments. Neuron. 1994;13:1235-44.

6. McClung CA, Nestler EJ. Regulation of gene expression and cocaine reward by CREB and DeltaFosB. Nat Neurosci. 2003;6:1208-15.

7. Nestler EJ. FosB: a transcriptional regulator of stress and antidepressant responses. Eur J Pharmacol. 2015;753:66-72.

8. Robison AJ, Nestler EJ. Transcriptional and epigenetic mechanisms of addiction Nat Rev Neurosci. 2011;12:623-37.

9. Russo SJ, Nestler EJ. The brain reward circuitry in mood disorders. Nat Rev Neurosci. 2013;14:609-25.

10. Heiman M, Schaefer A, Gong S, Peterson JD, Day M, Ramsey KE, et al. A translational profiling approach for the molecular characterization of CNS cell types. Cell. 2008;135:738-48.

11. Lobo MK, Karsten SL, Gray M, Geschwind DH, Yang XW. FACS-array profiling of striatal projection neuron subtypes in juvenile and adult mouse brains. Nat Neurosci. 2006;9:443-52.

12. Francis TC, Lobo MK. Emerging role for nucleus accumbens medium spiny neuron subtypes in depression. Biol Psychiatry. 2017;81:645-53.

13. Hamilton PJ, Burek DJ, Lombroso SI, Neve RL, Robison AJ, Nestler EJ, et al. Celltype specific epigenetic editing at the Fosb gene controls susceptibility to social defeat stress. Neuropsychopharmacology. 2017;43:272-84.

14. Lobo MK, Covington HE 3rd, Chaudhury D, Friedman AK, Sun H, Damez-Werno D, et al. Cell type-specific loss of BDNF signaling mimics optogenetic control of cocaine reward. Science (New York, NY). 2010;330:385-90.

15. Nestler EJ, Hyman SE. Animal models of neuropsychiatric disorders. Nat Neurosci. 2010;13:1161-9.

16. Vialou V, Robison AJ, Laplant QC, Covington HE 3rd, Dietz DM, Ohnishi YN, et al. DeltaFosB in brain reward circuits mediates resilience to stress and antidepressant responses. Nat Neurosci. 2010;13:745-52.

17. Krishnan V, Han MH, Graham DL, Berton O, Renthal W, Russo SJ, et al. Molecular adaptations underlying susceptibility and resistance to social defeat in brain reward regions. Cell. 2007;131:391-404.

18. Lobo MK, Zaman S, Damez-Werno DM, Koo JW, Bagot RC, DiNieri JA, et al. DeltaFosB induction in striatal medium spiny neuron subtypes in response to chronic pharmacological, emotional, and optogenetic stimuli. J Neurosci. 2013;33:18381-95.

19. Fox KR. The influence of physical activity on mental well-being. Public Health Nutr. 1999:2:411-8. 
20. Lai SM, Studenski S, Richards L, Perera S, Reker D, Rigler S, et al. Therapeutic exercise and depressive symptoms after stroke. J Am Geriatr Soc. 2006;54:240-7.

21. Lawlor DA, Hopker SW. The effectiveness of exercise as an intervention in the management of depression: systematic review and meta-regression analysis of randomised controlled trials. BMJ. 2001;322:763-7.

22. Mul JD. Voluntary exercise and depression-like behavior in rodents: are we running in the right direction? J Mol Endocrinol. 2018;60:R77-R95.

23. North TC, McCullagh P, Tran ZV. Effect of exercise on depression. Exerc Sport Sci Rev. 1990;18:379-415.

24. Perraton LG, Kumar S, Machotka Z. Exercise parameters in the treatment of clinical depression: a systematic review of randomized controlled trials. J Eval Clin Pract. 2010;16:597-604.

25. Dishman RK, Berthoud HR, Booth FW, Cotman CW, Edgerton VR, Fleshner MR, et al. Neurobiology of exercise. Obesity (Silver Spring). 2006;14:345-56.

26. Salmon P. Effects of physical exercise on anxiety, depression, and sensitivity to stress: a unifying theory. Clin Psychol Rev. 2001;21:33-61.

27. Greenwood BN, Foley TE, Le TV, Strong PV, Loughridge AB, Day HE, et al. Longterm voluntary wheel running is rewarding and produces plasticity in the mesolimbic reward pathway. Behav Brain Res. 2011;217:354-62.

28. Krawczewski Carhuatanta KA, Demuro G, Tschop MH, Pfluger PT, Benoit SC, Obici S. Voluntary exercise improves high-fat diet-induced leptin resistance independent of adiposity. Endocrinology. 2011;152:2655-64.

29. Obici S, Magrisso IJ, Ghazarian AS, Shirazian A, Miller JR, Loyd CM, et al. Moderate voluntary exercise attenuates the metabolic syndrome in melanocortin-4 receptor-deficient rats showing central dopaminergic dysregulation. Mol Metab. 2015:4:692-705.

30. Werme M, Messer C, Olson L, Gilden L, Thoren P, Nestler EJ, et al. Delta FosB regulates wheel running. J Neurosci. 2002;22:8133-8.

31. Nestler EJ, Carlezon WA Jr. The mesolimbic dopamine reward circuit in depression. Biol Psychiatry. 2006;59:1151-9.

32. Mul JD, Zheng J, Goodyear LJ. Validity assessment of 5 day repeated forced-swim stress to model human depression in young-adult C57BL/6J and BALB/CJ mice. eNeuro. 2016;3:6.

33. Lehmann ML, Herkenham M. Environmental enrichment confers stress resiliency to social defeat through an infralimbic cortex-dependent neuroanatomical pathway. J Neurosci. 2011;31:6159-73.

34. Paxinos G, Franklin K. The mouse brain in stereotaxic coordinates. 2nd edn. San Diego: Academic Press; 2001.

35. Perrotti LI, Hadeishi $Y$, Ulery PG, Barrot M, Monteggia L, Duman RS, et al. Induction of deltaFosB in reward-related brain structures after chronic stress. J Neurosci. 2004;24:10594-602.

36. Newton SS, Thome J, Wallace TL, Shirayama Y, Schlesinger L, Sakai N, et al. Inhibition of CAMP response element-binding protein or dynorphin in the nucleus accumbens produces an antidepressant-like effect. J Neurosci. 2002;22:10883-90.

37. Vialou V, Feng J, Robison AJ, Ku SM, Ferguson D, Scobie KN, et al. Serum response factor and CAMP response element binding protein are both required for cocaine induction of DeltaFosB. J Neurosci. 2012;32:7577-84.

38. Cahill ME, Bagot RC, Gancarz AM, Walker DM, Sun H, Wang ZJ, et al. Bidirectional synaptic structural plasticity after chronic cocaine administration occurs through Rap1 small GTPase signaling. Neuron. 2016;89:566-82.

39. Shuen JA, Chen M, Gloss B, Calakos N. Drd1a-tdTomato BAC transgenic mice for simultaneous visualization of medium spiny neurons in the direct and indirect pathways of the basal ganglia. J Neurosci. 2008;28:2681-5.

40. Grueter BA, Brasnjo G, Malenka RC. Postsynaptic TRPV1 triggers cell type-specific long-term depression in the nucleus accumbens. Nat Neurosci. 2010;13:1519-25.

41. Nimchinsky EA, Sabatini BL, Svoboda K. Structure and function of dendritic spines. Annu Rev Physiol. 2002;64:313-53.

42. Grueter BA, Robison AJ, Neve RL, Nestler EJ, Malenka RC. FosB differentially modulates nucleus accumbens direct and indirect pathway function. Proc Natl Acad Sci USA. 2013;110:1923-8.

43. Lee KW, Kim Y, Kim AM, Helmin K, Nairn AC, Greengard P. Cocaine-induced dendritic spine formation in D1 and D2 dopamine receptor-containing medium spiny neurons in nucleus accumbens. Proc Natl Acad Sci USA. 2006;103:3399-404.

44. Greenwood BN, Fleshner M. Exercise, learned helplessness, and the stressresistant brain. Neuromolecular Med. 2008;10:81-98.

45. Hunsberger JG, Newton SS, Bennett AH, Duman CH, Russell DS, Salton SR, et al. Antidepressant actions of the exercise-regulated gene VGF. Nat Med. 2007;13:1476-82.

46. Kim TK, Lee JE, Kim JE, Park JY, Choi J, Kim H, et al. G9a-mediated regulation of OXT and AVP expression in the basolateral amygdala mediates stress-induced lasting behavioral depression and its reversal by exercise. Mol Neurobiol. 2016:53:2843-56.

47. Fernandes MF, Matthys D, Hryhorczuk C, Sharma S, Mogra S, Alquier T, et al. Leptin suppresses the rewarding effects of running via STAT3 signaling in dopamine neurons. Cell Metab. 2015;22:741-9.

48. Dubreucq S, Durand A, Matias I, Benard G, Richard E, Soria-Gomez E, et al. Ventral tegmental area cannabinoid type-1 receptors control voluntary exercise performance. Biol Psychiatry. 2013;73:895-903.

49. Fediuc S, Campbell JE, Riddell MC. Effect of voluntary wheel running on circadian corticosterone release and on HPA axis responsiveness to restraint stress in Sprague-Dawley rats. J Appl Physiol (1985). 2006;100:1867-75.

50. Wallace DL, Han MH, Graham DL, Green TA, Vialou V, Iniguez SD, et al. CREB regulation of nucleus accumbens excitability mediates social isolation-induced behavioral deficits. Nat Neurosci. 2009;12:200-9.

51. Berton O, McClung CA, Dileone RJ, Krishnan V, Renthal W, Russo SJ, et al. Essential role of BDNF in the mesolimbic dopamine pathway in social defeat stress. Science (New York, NY). 2006:311:864-8.

52. Chaudhury D, Walsh JJ, Friedman AK, Juarez B, Ku SM, Koo JW, et al. Rapid regulation of depression-related behaviours by control of midbrain dopamine neurons. Nature. 2013;493:532-6.

53. Magistretti PJ, Allaman I. Lactate in the brain: from metabolic end-product to signalling molecule. Nat Rev Neurosci. 2018;19:235-49.

54. Tye KM, Mirzabekov JJ, Warden MR, Ferenczi EA, Tsai HC, Finkelstein J, et al. Dopamine neurons modulate neural encoding and expression of depressionrelated behaviour. Nature. 2013;493:537-41.

55. Duman RS, Monteggia LM. A neurotrophic model for stress-related mood disorders. Biol Psychiatry. 2006;59:1116-27.

56. Maze I, Covington HE 3rd, Dietz DM, LaPlant Q, Renthal W, Russo SJ, et al. Essential role of the histone methyltransferase G9a in cocaine-induced plasticity. Science (New York, NY. 2010;327:213-6.

57. Robison AJ, Vialou V, Mazei-Robison M, Feng J, Kourrich S, Collins $M$, et al. Behavioral and structural responses to chronic cocaine require a feedforward loop involving DeltaFosB and calcium/calmodulin-dependent protein kinase II in the nucleus accumbens shell. J Neurosci. 2013;33:4295-307.

58. Golden SA, Christoffel DJ, Heshmati M, Hodes GE, Magida J, Davis K, et al. Epigenetic regulation of RAC1 induces synaptic remodeling in stress disorders and depression. Nat Med. 2013;19:337-44.

59. Christoffel DJ, Golden SA, Dumitriu D, Robison AJ, Janssen WG, Ahn HF, et al. IkappaB kinase regulates social defeat stress-induced synaptic and behavioral plasticity. J Neurosci. 2011;31:314-21.

60. Dumitriu D, Laplant Q, Grossman YS, Dias C, Janssen WG, Russo SJ, et al. Subregional, dendritic compartment, and spine subtype specificity in cocaine regulation of dendritic spines in the nucleus accumbens. J Neurosci. 2012;32:6957-66.

61. Ruegsegger GN, Toedebusch RG, Childs TE, Grigsby KB, Booth FW. Loss of Cdk5 function in the nucleus accumbens decreases wheel running and may mediate age-related declines in voluntary physical activity. J Physiol. 2017;595:363-84.

62. Fisher BE, Li Q, Nacca A, Salem GJ, Song J, Yip J, et al. Treadmill exercise elevates striatal dopamine D2 receptor binding potential in patients with early Parkinson's disease. Neuroreport. 2013;24:509-14.

63. Robertson CL, Ishibashi K, Chudzynski J, Mooney LJ, Rawson RA, Dolezal BA, et al. Effect of exercise training on striatal dopamine D2/D3 receptors in methamphetamine users during behavioral treatment. Neuropsychopharmacology. 2016;41:1629-36. 